\title{
American College of Medical Toxicology Position Statement on Post-Chelator Challenge Urinary Metal Testing
}

\author{
American College of Medical Toxicology
}

Published online: 31 March 2010

(C) American College of Medical Toxicology 2010

Keywords Urinary metal testing · Post-chelation testing

Heavy metals, such as lead and mercury, are ubiquitous in the environment [1-3]. Exposure in human populations is constantly occurring, and detectable levels of lead and mercury are commonly found in blood and urine of individuals who have no clinical signs or symptoms of toxicity and may be considered background or reference values [15]. Although urine testing for various metals in an appropriate clinical context, using proper and validated methods, is common and accepted medical practice, the use of postchallenge (a.k.a., post-provocation) urine metal testing, wherein specimens are typically collected within $48 \mathrm{~h}$ of chelation agent administration, is fraught with many misunderstandings, pitfalls, and risks. The American College of Medical Toxicology issues this position statement in disapproval of the use of post-challenge urinary metal testing in clinical practice and the use of such test results as an indication for further administration of chelating agents.

In current evidence-based medical practice, urinary testing is commonly used in the biomonitoring of exposure to certain metals such as arsenic and inorganic mercury and the severity of their associated toxicity. It is accepted practice to conduct such testing, e.g., in exposed individuals with clinical evidence of peripheral neuropathy, as long as validated collection and analytical methods are employed prior to, or after, a sufficiently long time interval (e.g., 3-

American College of Medical Toxicology

10645 N. Tatum Blvd., Suite 200-111,

Phoenix, AZ 85028, USA

URL: www.acmt.net
5 days) following administration of a chelating agent, i.e., applied to non-challenge urine specimens, and the results are compared to appropriate reference values $[5,6]$. In some non-evidence-based medical practices, however, assessment of metal poisoning is frequently based on non-validated postchallenge urine metal testing, which invites inappropriate comparison to normal urine reference ranges [4-7].

Chelating agents such as dimercaptosuccinic acid (DMSA), dimercaptopropanesulfonic acid (DMPS), dimercaprol, and edetate calcium disodium $\left(\mathrm{CaNa}_{2}-\mathrm{EDTA}\right)$ bind metallic and metalloid elements and have been shown to increase their elimination from the body. Chelating agents have been found to mobilize metals in healthy individuals who have a body burden considered normal for a standard reference population, as well as in those who are determined to have a high body burden of the same metallic species $[4,8-11]$. More specifically, urine specimens collected in relatively close temporal proximity to administration of chelating agents, i.e., post-challenge specimens, are expected to have increased concentrations of metallic elements. This includes elements, such as zinc, that are essential to normal physiologic functions and maintenance of good health.

Normal reference values for non-challenge urine metal test results vary among and within different populations. Ranges for these values have been established in nationally certified laboratories that meet proficiency standards for urinary metal testing [5]. However, scientifically acceptable normal reference values for post-challenge urine metal testing have not been established [10]. In addition, scientific investigation to date has failed to establish a valid correlation between prior metal exposure and post-challenge test values [10]. Despite the lack of scientific support to do so, it is also a common practice of some laboratories and care providers to provide or apply non-challenge normal reference values as 
a comparative means of interpreting results of post-challenge urine metal testing [5]. Currently, available scientific data do not provide adequate support for the use of post-challenge urine metal testing as an accurate or reliable means of identifying individuals who would derive therapeutic benefit from chelation.

Unfortunately, the practice of post-challenge urine metal testing and its application to assessment of metal poisoning often leads to unwarranted and prolonged oral and/or intravenous administration of chelating agents, in response to the results of serial post-challenge testing that remain elevated above non-challenge reference values. Chelation therapy based on such laboratory values, in addition to being of no benefit to patient outcome, may actually prove harmful $[5$, 12]; catastrophic outcomes such as acute fatal hypocalcemia have been reported following the improper use of a chelating agent, edetate disodium ( $\left.\mathrm{Na}_{2}-\mathrm{EDTA}\right)$ [13]. In addition, the safer formulation of this agent, $\mathrm{CaNa}_{2}-\mathrm{EDTA}$, has been demonstrated to increase urinary excretion of essential minerals such as iron, copper, and zinc $[8,14]$. There is published experimental evidence that deleterious effects may occur when chelation is applied in the absence of prior lead exposure [15]. Other chelating agents such as DMSA and DMPS may also increase the elimination of certain essential elements, as well as promote target organ redistribution of metallic elements of concern such as mercury [16-18].

It is, therefore, the position of the American College of Medical Toxicology that post-challenge urinary metal testing has not been scientifically validated, has no demonstrated benefit, and may be harmful when applied in the assessment and treatment of patients in whom there is concern for metal poisoning.

Disclosure This statement has been developed by members of the ACMT with principal contribution in writing by Nathan Charlton, M.D. and Kevin L. Wallace, M.D., F.A.C.M.T., reviewed and approved by the ACMT Practice Committee and Board of Directors, and opened to comment by all members of the College. Disclosure statements for participating members of the ACMT Practice Committee and ACMT Board of Directors are available. June 2009

\section{References}

1. Anonymous (2007) Toxicological profile for lead. US Department of Health and Human Services-Agency for Toxic Substances and Disease Registry, Atlanta

2. Anonymous (1999) Toxicological profile for mercury. US Department of Health and Human Services-Agency for Toxic Substances and Disease Registry, Atlanta
3. Brodkin E, Copes R, Mattman A, Kennedy J, Kling R, Yassi A (2007) Lead and mercury exposures: interpretation and action. CMAJ 176(1):59-63

4. Kales SN, Goldman RH (2002) Mercury exposure: current concepts, controversies, and a clinic's experience. J Occup Environ Med 44(2):143-154

5. Risher JF, Amler SN (2005) Mercury exposure: evaluation and intervention. The inappropriate use of chelating agents in the diagnosis and treatment of putative mercury poisoning. NeuroToxicology 26 (4):691-699

6. Vamnes JS, Eide R, Isrenn R, Hol PJ, Gjerdet NR (2000) Diagnostic value of a chelating agent in patients with symptoms allegedly caused by amalgam fillings. J Dent Res 79(3):868874

7. McKay C, Holland M, Nelson L (2003) A call to arms for medical toxicologists: the dose, not the detection, makes the poison. Internet J Med Toxicol 6(1):1

8. Kalia K, Flora SJS (2005) Strategies for safe and effective therapeutic measures for chronic arsenic and lead poisoning. J Occup Health 47 (1): $1-21$

9. Bell RF, Gilliland JC, Boland JR, Sullivan BR (1956) Effect of oral edathamil calcium-disodium on urinary and fecal lead excretion; comparative excretory studies with intravenous therapy. AMA Arch Ind Health 13(4):366-371

10. Frumkin H, Manning CC, Williams PL, Sanders A, Taylor BB, Pierce M, Elon L, Hertzberg VS (2001) Diagnostic chelation challenge with DMSA: a biomarker of long-term mercury exposure? Environ Health Perspect 109(2):167-171

11. Fayez I, Paiva M, Thompson M, Verjee Z, Koren G (2005) Toxicokinetics of mercury elimination by succimer in twin toddlers. Pediatric Drugs 7(6):397-400

12. Dietrich KN, Ware JH, Salganik M, Radcliffe J, Rogan WJ, Rhoads GG, Fay ME, Davoli CT, Denckla MB, Bornschein RL, Schwarz D, Dockery DW, Adubato S, Jones RL, for the Treatment of Lead-Exposed Children Clinical Trial Group (2004) Effect of chelation therapy on the neuropsychological and behavioral development of lead-exposed children after school entry. Pediatrics 114(1):19-26

13. Brown MJ, Willis T, Omalu B, Leiker R (2006) Deaths resulting from hypocalcemia after administration of edetate disodium: 2003-2005. Pediatrics 118(2):e534-e536

14. Powell JJ, Burden TJ, Greenfield SM, Taylor PD, Thompson RPH (1999) Urinary excretion of essential metals following intravenous calcium disodium edetate: an estimate of free zinc and zinc status in man. J Inorganic Biochem 75(3):159-165

15. Stangle DE, Smith DR, Beaudin SA, Stawderman MS, Levitsky DA, Strupp BJ (2007) Succimer chelation improves learning, attention, and arousal regulation in lead-exposed rats but produces lasting cognitive impairment in the absence of lead exposure. Environ Health Persp 115(2):201-209

16. Chisolm JJ, Thomas DJ (1985) Use of 2, 3-dimercaptopropane-1sulfonate in treatment of lead poisoning in children. J Pharmacol Exp Ther 235(3):665-669

17. Smith DR, Calacsan C, Woolard D, Luck M, Cremin J, Laughlin NK (2000) Succimer and the urinary excretion of essential elements in a primate model of childhood lead exposure. Toxicol Sci 54(2):473-480

18. Rooney JPK (2007) The role of thiols, dithiols, nutritional factors and interacting ligands in the toxicology of mercury. Toxicology 234(3):145-156 